\title{
ANALISIS PENGGUNAAN PARTIKEL AKHIRAN SHUUJOSHI 'NE' DAN 'YO’ PADA NOVEL “SABIRU KOKORO”
}

\author{
Rudi Hartono Manurung \\ Japanese Department, Faculty of Language and Culture, Bina Nusantara University, \\ Jln. Kemanggisan Ilir III No. 45, Kemanggisan/Palmerah, Jakarta Barat 11480, \\ rmanurung@binus.edu
}

\begin{abstract}
Shuujoshi is a particle in the end of a sentence which shows speaker's feeling and influence listener's. Shuujoshi ne and yo have meaning differences as functional distinction that make the two articles divided into each functionalization. Using shuujoshi ne and yo is related with speaker's consideration towards information of listener. It is noted that Shuujoshi ne, used by speaker when he has the same perception with listener. Meanwhile, using shuujoshi yo happens when there is different statements from speaker and listener's perception. Besides, there is also meaning differences among shuujoshi ne and the like, and also among shuujoshi yo and the like. Therefore, when learners of Japanese language learn about shuujushi ne and yo, they will not rely on text books only.
\end{abstract}

Keywords: shuujoshi, ne, yo

\begin{abstract}
ABSTRAK
Shuujoshi adalah Partikel yang melekat di akhir kalimat dan menunjukkan perasaan penutur dan mempengaruhi perasaan pendengar ketika penutur mengucapkan kalimat tersebut. Shuujoshi ne dan yo memiliki perbedaan makna sebagai pembeda fungsi, yang kemudian membuat kedua partikel tersebut terbagi dalam fungsialisasinya masing-masing. Penggunaan shuujoshi ne dan yo berhubungan erat dengan pertimbangan penutur terhadap informasi yang dimiliki oleh pendengar, Perlu diperhatikan bahwa Shuujoshi ne, digunakan oleh penutur saat dia mempunyai kesamaan persepsi dengan pendengarnya.sedangkan penggunaan shuujoshi yo terjadi apabila pernyataan penutur berbeda dengan persepsi si pendengarnya. Selain itu juga terdapat perbedaan makna yang besar diantara sesama shuujoshi ne dan sesama shuujoshi yo. Sehingga bagi para pembelajar bahasa Jepang pada saat mempelajari Shuujoshi ne dan yo tidak cukup hanya berpedoman pada buku teks saja.
\end{abstract}

Kata kunci: Shuujoshi,ne,yo 


\section{PENDAHULUAN}

Dalam bahasa Jepang tingkat pemakaian joshi (partikel) atau kata bantu amat tinggi terutama dalam bahasa tulisan. Hal inilah yang menjadi kesulitan bagi para pemelajar bahasa Jepang terutama di Indonesia, karena dalam bahasa Indonesia hanya ada sedikit kata bantu. Dalam bahasa Jepang partikel (助詞) mempunyai fungsi yang penting dalam membentuk suatu kalimat. Mengingat pentingnya partikel dalam bahasa Jepang dalam menentukan arti kalimat, Sudjianto \& Dahidi (2004) memberikan pengertian tentang partikel sebagai berikut:

“Partikel (助詞) adalah kelas kata yang termasuk fuzokugo dipakai setelah suatu kata untuk menunjukkan hubungan antara kata tersebut dengan kata lain serta untuk menambah arti kata tersebut lebih jelas lagi.

(Sudjianto \& Dahidi, 2004:181)

Secara garis besar, partikel dalam bahasa Jepang dibagi dalam empat jenis, yaitu: kakujoshi, fukujoshi, setsuzokujoshi dan shuujoshi. Menurut Sudrajat (2001) yang dimaksud dengan Kakujoshi adalah kata bantu atau partikel yang digunakan untuk mempertegas kata. Partikel yang termasuk dalam kakujoshi adalah: が、の、を、に、へ、と、から、より、で、た. Fukujoshi adalah kata bantu yang fungsinya dapat menambah pengertian kalimat semakin mendalam. Kata Bantu yang termasuk dalam fukujoshi adalah: は、も、こそ、さえ、でも、しか、まで、ばかり、だけ、ほ じ、くらい、など、きり、なり、やら、か、だの. Setsuzokujoshi adalah kata bantu yang dipakai untuk menjelaskan kata/kalimat sebelumnya. Kata bantu setsuzokujoshi antara lain adalah: ば、と、 ても、けれど、が、のに、ので、から、し、て、ながら、たり、ものの、ところで. Sedangkan yang dimaksud dengan Shuujoshi adalah kata bantu yang digunakan diakhir ungkapan/ kalimat dan merupakan ungkapan perasaan penuturnya. Yang termasuk dalam kata bantu shuujoshi adalah: か、な、や、ぞ、とも、よ、の、わ、ね、さ. Shuujoshi merupakan partikel yang menunjukkan; memerlukan pendapat yang sama, menegaskan pendapat yang sama, pernyataan yang kuat dan lain-lain terhadap lawan bicara.

Ciri khas shuujoshi adalah posisinya yang selalu terletak di akhir kalimat. Sedangkan dalam Bahasa Indonesia yang dimaksud dengan partikel adalah kata yang biasanya tidak dapat di derivisikan atau di infleksikan, yang mengandung makna gramatikal dan tidak mengandung makna leksikal, termasuk di dalamnya kata sandang, preposisi, konjungsi dan interjeksi. Dilihat dari jumlah partikel dalam bahasa Indonesia yang sedikit, inilah yang menjadi kendala bagi para pemelajar bahasa Jepang dalam memahami bagaimana perbedaan antara shuujoshi "ne" dan "yo" dimana para pemelajar asing Indonesia yang bahasa ibunya Bahasa Indonesia sering salah memahami mengenai perbedaan kedua shuujoshi ini. Tujuan penulis mengadakan penelitian, agar para pemelajar Bahasa Jepang dapat mengetahui perbedaan yang jelas antara shuujoshi ne dan yo yang ditempatkan di akhir kalimat, pada pemaknaanya, sehingga penggunaan kalimat-kalimat Bahasa Jepang selanjutnya akan lebih baik dan tidak aneh di telinga penutur aslinya. Dalam penelitian shujoshi ne dan yo ini penulis menggunakan novel “Sabiru Kokoro”「錆びる心」 yang merupakan hasil karya dari Natsuo Kirino - 桐野夏雄. (1997) sebagai sumber data, dimana didalamnya terdapat cukup banyak percakapan yang menggunakan shujoshi ne dan yo. Dengan adanya novel sebagai sumber data ini penulis berharap gambaran situasi pemakaian shujoshi ne dan yo akan terlihat lebih jelas.

\section{METODE PENELITIAN}

Dalam penelitian ini metode yang digunakan penulis terdiri atas dua metode, yaitu metode deskriptif dan metode kepustakaan. Metode deskriptif adalah metode dengan cara kerja membahas suatu masalah dengan menata dan mengklasifikasikan serta memberi penjelasan tentang gejala-gejala 
yang tampak pada data tanpa melakukan pengujian. Dan yang dimaksud dengan metode kepustakaan yaitu cara pengumpulan data yang dilakukan terhadap sejumlah naskah tertulis yang merupakan sumber data. Dalam penelitian ini metode deskriptif dilakukan pada tahap penelitian data sedangkan metode kepustakaan dilakukan pada tahap pengumpulan data.

\section{Kajian Teori Shuujoshi}

Niwa (2004) - 庭三郎 mengatakan とも、や、っけ、って、か、ぜ、ぞ、さ、わ、よ、 ね disebut sebagai shuujoshi dengan definisi sebagai berikut :

$$
\text { しゅうじょし }
$$

終助詞は、文のいちばん終わりについて、その文を言うときの、話し手の、その文を 受け取る相手に対する「働きかけの気持ち」を示す助詞。聞き手に対して同意を求めた り、確認をしたり、強く主張したりします。＜複合述語 $>$ のところで扱うくムード $>$ の類に似たものですが形が小さく、それ自体は変化しないことが特徴です。

Terjemahan

Shuujoshi adalah Partikel yang melekat di akhir kalimat dan menunjukkan perasaan penutur dan mempengaruhi perasaan pendengar ketika penutur mengucapkan kalimat tersebut. Dan juga meminta tuntutan yang kuat, penegasan, dan meminta persetujuan terhadap pendengar. Dengan jenis "nuansa" dalam "predikat majemuk" sangat mirip, tetapi bentuknya sangat sedikit dan keistimewaaannya adalah bentuknya yang tidak berubah.

(Niwa, 2004)

Berikut ada beberapa definisi mengenai shuujoshi ne dan yo, yang definisinya sebagai berikut: Masuoka Takashi (1991: 94) menyatakan beberapa penggunaan shuujoshi Ne dan yo. Konsep-konsep penggunaan ne dan yo yang dibahas di dalam buku tersebut, dia susun berdasarkan pemikiran dari Takubo dan Ooso, tentang fungsi dua shuujoshi diatas. Masuoka menegaskan bahwa penggunaan shuujoshi ne dan yo berhubungan erat dengan pertimbangan penutur terhadap informasi yang dimiliki oleh pendengar, berdasarkan penelitian Takubo. Ada tiga penggunaan shujoshi ne yang disusun oleh Masuoka berdasarkan penelitian Ooso yaitu:

1. Meminta kepastian / penegasan. <確認を求める用法>

.ハンバーグ定食二つにグラタン一つでございます㸚。

'Dua paket hamburger dan satu gratis ya.'

2. Meminta persetujuan. <同意を求める用法 $>$

今日は金曜日ですね。

'Hari ini hari Jumat kan?'

3. Memberi komentar tentang hal-hal yang termasuk dalam wilayah pendengar.

＜聞き手の領 域に属するものにコメントする用法＞

すてきなブラウスですね。

'Blusnya bagus deh.'

(Masuoka, 1991: 95)

Kesamaan dari ketiga penggunaan fungsi ne adalah bahwa informasi dan pertimbangan yang dimiliki oleh penutur sama dengan yang dimiliki pendengar. Mengenai fungsi yo Ooso (dalam Masuoka, 1991) menjelaskan sebagai berikut:

1. Menyangkal/membantah penilaian dan pertimbangan pendengar yang dianggap berbeda dengannya. <相手が自分と違う判断をくだしていると知って、それに、反論 する用 法>

---アメリカ人はあまり働きませんね。 
'....Orang Amerika tidak terlalu rajin bekerja ya.'

---いや、よく働きますよ。

'....Ah tidak, rajin bekerja kok.'

2. Mengingatkan hal yang kiranya terlupakan oleh pendengar. <聞き手が忘れているような ことを指摘し、思い出させるような用法＞

---もも九時ですよ。

'Sudah jam sembilan loh.'。

3. Menyampaikan hal yang tidak disadari dan tidak diketahui oleh pendengar. <聞き手が気が ついていないこと、知らないことを伝える上で、話してと聞き手の情報、判断の食 い違いを前提する用法>

----上着に何かついていますよ。

'Di jaketmu ada sesuatu yang melekat loh.'

(Masuoka, 1991: 95)

Kesamaan dari ketiga pemakaian yo tersebut adalah bahwa informasi dan pertimbangan yang dimiliki penutur berbeda dengan yang dimiliki pendengar. Masuoka menegaskan mengenai hal itu sebagai berikut:

我々は自分が持っている知識を聞き手に伝えるに際して、聞き手が 持っていると 想定される知識のあり方と異同を判断し、それを表明するということである。そし て、話しての知識と聞き手の知識が基本的に一致すると判断される場合には＜ね >が用いられ、両者の間にずれがあり、その意味で両者が対的な関係にあると判断 される場合には <よ>が用いられるわけである。

Terjemahan :

Dengan demikian, ketika penutur menyampaikan informasi kepada pendengar, ia mempertimbangkan apakah pendengar juga memiliki informasi tersebut atau tidak. Bila penutur mempertimbangkan bahwa informasi yang dimilikinya pada dasarnya sama dengan yang dimiliki pendengar, maka dipakai shuujoshi ne. Dan bila dipertimbangkan bahwa informasi yang dimiliki pendengar berbeda dengan yang dimilikinya, maka dipakai shuujoshi yo.

Contoh :

1. 今日は誰もお客見えてませんよ。（さびしんぼう）

'Hari ini tidak ada seorang pun tamu yang kelihatan'.

2. お島って変わった名ですね。（市川森一<夢の島＞）

'Ooshima itu nama yang aneh ya'

Shuujoshi yo pada contoh (1) menunjukkan asumsi penutur bahwa mungkin lawan bicara tidak mengetahui isi informasi tersebut. Sebaliknya, pada contoh (2) shuujoshi ne menunjukkan perkiraan penutur bahwa lawan bicara juga memiliki informasi yang sama yaitu bahwa nama Ooshima merupakan nama yang aneh. (Masuoka, 1991: 96)

Pemikiran Ooso dan Takubo mengenai shuujoshi ne dan yo tersebut diatas dijadikan dasar pemikiran oleh Masuoka dalam menerangkan hal-hal sehubungan dengan pemakaian shuujoshi ne dan yo dalam kalimat bentuk tanya ( 疑問型 $)$ dan kalimat bentuk menuntut/memohon ( 挀え型 $)$. Dalam 
kalimat percakapan bentuk tanya, shuujoshi ne dan yo jarang sekali digunakan. Pada bentuk tanya, yaitu penutur meminta informasi kepada pendengar, pada prinsipnya diasumsikan bahwa informasi yang dimiliki pendengar melebihi informasi yang dimiliki penutur. Oleh karena itu pada kalimat percakapan bentuk tanya tidak perlu mempersiapkan secara khusus perbedaan informasi si penutur dan pendengar. Dan inilah yang menyebabkan rendahnya frekwensi pemakaian shuujoshi ne dan yo dalam kalimat tanya. Walaupun demikian, untuk shuujoshi ne ada sedikit kekhususan.

Ada dua keadaan yang memungkinkan dipakainya shuujoshi ne dalam kalimat percakapan bentuk tanya, yaitu:

1. Shuujoshi ne dapat dipakai dalam kalimat percakapan bentuk tanya bila informasi pendengar dianggap dapat mengisi ketidakpastian informasi penutur. く話してが自分の不確かな知識 を聞き手の情報によって補おうとする場合でる>

会議は 1 時からでしたかね。

'Rapatnya dimulai dari jam satu ya?'

(Masuoka, 1991: 97)

Pada contoh (1) penutur tidak pasti akan informasi yang dimilikinya, dan meminta kebenaran informasinya tersebut kepada pendengar. Pembicara mengasumsikan bahwa informasinya sama dengan informasi lawan bicara.

\section{\{一のだ「一んだ」\}の形式を伴う疑問語疑問文の場合である”}

2. Shuujoshi ne dapat dipakai dalam kalimat percakapan bentuk tanya dengan kata tanya pada pola kalimat “.....no da $\{n d a\}$ “

さっき誰と話していたんだね。

'Tadi bicara dengan siapa sih?'

Pemakaian shuujoshi ne pada contoh (1) di atas bukan berarti bahwa penutur mempertimbangkan informasi yang dimiliki oleh pendengar. Melainkan memberi efek memperlunak nada tanya.

(Masuoka, 1991: 97)

Untuk kalimat bentuk menunutut atau memohon, sering diikuti shuujoshi ne dan yo.

Contoh :

1.もっとイイコになってよ。(さびしんぼう)

'Jadilah anak yang lebih baik'. かんちが

2. 変な勘違いしないでね。(夢の島）

'Jangan salah paham ya.'

(Masuoka, 1991: 98)

Ne dan yo yang muncul pada kalimat menuntut/memohon seperti contoh (1) dan (2) di atas tidak menunjukkan persamaan dan perbedaan informasi penutur dan pendengar, melainkan maksud penutur dan pendengar.Masuoka menjelaskan bahwa shuujoshi ne dan yo yang muncul dalam kalimat bentuk menuntut/memohon ini merupakan ne dan yo yang menunjukkan persamaan dan perbedaan maksud antara penutur dan pendengar. Dengan kata lain, ketika kita meminta kepada pendengar untuk bertindak sesuatu, shuujoshi ne dan yo dapat menunjukkan pertimbangan penutur apakah maksud pendengar sesuai atau tidak dengan maksudnya. Dengan dasar pemikiran ini dapat dijelaskan efekefek dari pemakaian shuujoshi ne dan yo pada kalimat bentuk menuntut/memohon. Dan perlu dijelaskan bahwa yang dimaksud dengan kalimat bentuk menuntut/memohon oleh Masuoka di sini adalah kalimat yang menunjukkan permohonan, ajakan, perintah dan larangan. 
Dalam kalimat perintah dan larangan, shuujoshi yo dapat dipakai.

Contoh:

(1) 放っといてくれよ。(さびしんぼう)

'Biarkan aku sendiri!'

(2) 病院に行けよ。(キネマの天地)

'pergilah ke rumah sakit!'

(3) 変なこと言うなよ。(さびしんぼう)

'Jangan bicara yang aneh-aneh!'

(4) ふざげんじゃないよ。(さびしんぼう)

'Ini bukan lelucon!'

(Masuoka , 1991: 99)

Pengertian yang paling dasar dari ekspresi perintah dan larangan, yaitu penutur memaksa pendengar untuk melakukan suatu tindakan yang bertentangan dengan maksud pendengar itu sendiri. Dengan pengertian seperti itu, bila shuujoshi yo dipakai ketika penutur meminta pendengar untuk berbuat sesuatu, akan menunjukkan bahwa penutur bukan hanya meminta saja tapi juga memperkirakan bahwa tindakan yang dimintanya itu bertentangan dengan maksud pendengar. Ini menunjukkan bahwa pembicara sedikit banyak juga memperhatikan dan mempertimbangkan maksud pendengar, pemakaian shuujoshi yo pada kalimat perintah dan larangan akan memperlunak ekspresi tersebut. Berbeda dengan yo, pemakaian shuujoshi ne dalam kalimat perintah dan larangan adalah aneh atau tidak sesuai.

Contoh :

(1) 放っといてくれね。

'Biarkan aku sendiri ya!'

(2) 病院に行け放。

'Pergilah ke rumah sakit ya!'

(3).変なこと言うなね。

'Jangan bicara yang aneh-aneh ya!'

(4)ふざけんじゃないね。

'ini bukan lelucon ya!'

(Masuoka, 1991: 99)

Sifat dasar dari kalimat perintah dan larangan, yaitu memaksa pendengar untuk melakukan suatu tindakan yang bertentangan dengan maksud pendengar, ini tidak sesuai dengan sifat shuujoshi ne yang menunjukkan maksud yang sama antara penutur dan pendengar. Dengan demikian, shuujoshi ne tidak dapat dipakai dalam kalimat perintah dan larangan. Dan bila diperkirakan bahwa maksud pendengar sama dangan penutur, maka penutur tidak perlu memakai ekspresi perintah dan larangan. Pada kalimat permohonan, baik shuujoshi ne maupun yo dapat digunakan.

Contoh :

(1) 仲良くしてやってくださいね。（さびしんぼう）

'Bertemanlah!'

(2) しばらくいっしょにいてね。（さびしんぼう）

'Temani sebentar ya!'

(3) 見に来てくださいよ。（さびしんぼう）

'Datanglah untuk melihat sebentar!'

(4) 今度紹介して下さいよ。(市川森一<グッバイ.ミュージック.メイト＞)

'Lain kali kenalkan loh!'

(Masuoka, 1991: 100)

Berbeda dengan kalimat perintah dan larangan, kalimat permohonan pada dasarnya merupakan ekspresi yang menghormati dan menghargai pendengar, tidak memaksakan suatu 
perbuatan. Karena itu kalimat permohonan lebih sopan dari pada kalimat perintah dan larangan. Dengan kata lain, penutur merasa yakin akan memperoleh persetujuan pendengar. Dengan demikian, shuujoshi ne tidak dapat muncul bersama-sama dengan ekspresi yang menunjukkan ketidakpastian apakah persetujuan pendengar dapat diperoleh atau tidak.

Contoh :

(1) 仲良くしてやってくださいね。だめですか。 'Bertemanlah! Tidak boleh?'

(2) しばらくいっしょにいてね。だめ?

'Temani sebentar ya! Tidak boleh?'

(Masuoka, 1991: 100)

Biasanya bila pada kalimat permohonan diberi shuujoshi yo, maka perasaan penutur yang memohon kepada pendengar diekspresikan lebih kuat. Hal ini disebabkan karena walaupun penutur sudah mengasumsikan bahwa maksud pendengar berbeda dengan maksudnya, ia (penutur) tetap bersikeras memohon kepada pendengar. Kalimat permohonan dengan ekspresi seperti "onegaidesukara" yang menunjukkan dengan kuat perasaan memohon, akan lebih sesuai bila diberi shuujoshi yo.

Contoh :

(1) お願いですから、今度紹介して下さいよ。

'Tolonglah, lain kali dikenalkan ya!'

(2) お願いですから、今度紹介して下さい。

'Tolonglah lain kali dikenalkan!'

Berbeda dengan ne, shuujoshi yo dapat dipakai bersama-sama dengan ekspresi "dame desuka", karena pemakaian shuujoshi yo menunjukkan tidak adanya harapan penutur untuk memperoleh persetujuan dari pendengar.

(3) 今度紹介して下さいよ。だめですか。 'Lain kali kenalkan lho! Tidak boleh?'

Pemakaian shuujoshi ne dan yo pada kalimat ajakan sama dengan pemakaiannya pada kalimat permohonan. Contoh :

(4) じや、また明日会おうね。（さびしんぼう）

'Jadi, sampai bertemu lagi besok ya!'

(5) いっしょに行こうよ。

'Pergi sama-sama dong!'

(Masuoka, 1991: 101)

Pemakaian shuujoshi ne yang menunjukkan pertimbangan bahwa maksud penutur sama dengan pendengar, akan menimbulkan nuansa bahwa besar kemungkinan pendengar akan melakukan atau menerima ajakan penutur. Sebaliknya, pada pemakaian yo yang menunjukkan asumsi bahwa pendengar mempunyai maksud yang berbeda, maka akan menimbulkan nuansa bahwa penutur mengajak lawan bicara secara paksa. Dalam keadaan ini penutur tidak yakin apakah pendengar akan menyetujui/menerima ajakannya atau tidak, sehingga setelah shuujoshi yo dapat diikuti ekspresi yang menunjukkan ketidakpastian seperti "dame desu ka", dan ekspresi pengulangan.

Contoh :

(1) いっしょに行こうよ。だめ?

'Pergi sama-sama dong! Tidak boleh ?'

(2) いっしょに行こうよ。ねえ、行こうよ。

'Pergi sama-sama dong! Ya, pergi dong!' 
Untuk shuujosji ne, pemakaian seperti contoh (3) dan contoh (4) tidak boleh.

(3) また明日会おうね。だめ?

'Sampai bertemu lagi besok ya ! Tidak boleh ?'

(4)また明日会おうね。亦え、会おうね。

'Sampai bertemu lagi besok ya ! ya ketemu lagi ya!'

(Masuoka, 1991: 102)

\section{HASIL DAN PEMBAHASAN}

\section{Fungsi Shuujoshi Ne}

Berdasarkan analisis yang telah penulis lakukan dalam korpus data yaitu novel "sabiru kokoro", fungsi-fungsi shuujoshi ne dapat dengan jelas mengapresiasikan situasi dan perasaan si pemakainya. Fungsi-fungsi yang penulis temukan adalah sebagai berikut:

\section{Fungsi shuujoshi ne sebagai “meminta kepastian / penegasan”.}

Contoh kalimat dalam novel "Sabiru kokoro"

1.つまり、Hさんはものを創める人なのですね。（hal. 13）

'Oh, kalau begitu si $\mathrm{H}$ itu orangnya suka memulai sesuatu yang baru ya.'

(Situasi: Di sebuah kafe Mizue dan Morizaki \{kedua-duanya wanita\} bercakap-cakap mengenai $\mathrm{H}$ pria yang dicintai oleh Morizaki)

Analisis penggunaan $\downarrow_{2}$ : Ketika Mizue berbicara kepada Morizaki, dia mencoba memastikan informasi yang didapat dari Morizaki, mengenai $\mathrm{H}$ dan mencoba menyimpulkannya. Dengan kata lain dia meminta kepastian kepada Morizaki mengenai jati diri $\mathrm{H}$.

2. 変な名前ね。(hal. 17)

'Nama yang aneh ya.'

(Situasi: Didalam kafe Morizaki dan Mizue bercakap-cakap mengenai nama sebuah teater yang diambil dari nama sebuah sel)

Analisis penggunaan $\downarrow$ : Mizue memberitahu temannya nama teater sandiwara yang diambil dari nama sejenis sel, setelah mendengar nama itu Morizaki merasa aneh. Sehingga ia mencoba meminta penegasan lawan bicaranya bahwa nama itu adalah nama yang aneh.

3. 森崎さんともそういうご緣があるのですね。(hal. 18)

'Morisaki, kamu ini selalu terlibat hal yang seperti itu ya.'

(Situasi: Didalam kafe Mizue bercerita kepada Morizaki mengenai kegiatannya yang selalu berhubungan dengan penelitian sel)

Analisis penggunaan $\downarrow$ : Mizue selalu terlibat dalam penelitian sel. Karena itu, temannya Mizue yang sudah mengetahui hal itu meminta kepastian/penegasan sekali lagi terhadap lawan bicaranya tersebut.

4. あいつ、女の話嫌いみたいですね。（hal. 165）

'Sepertinya dia tidak suka topik pembicaraan mengenai wanita ya.'

(Situasi: Didalam kantor pada saat rapat para petinggi yakuza, Miyata (anak buah Sakurai) menjawab pertanyaan dari Sakurai yang merupakan pimpinan yakuza)

Analisis penggunaan $\mathfrak{l}_{2}$ : Sakurai bertanya kepada Miyata mengenai Shimajiri. Miyata sudah mengetahui sifat dari orang yang ditanyakan oleh Sakurai tersebut, tetapi Miyata tidak pasti akan informasinya, sehingga kalimat yang ia utarakan berbentuk meminta kepastian kepada temannya yang lain. 


\section{Fungsi shuujoshi ne sebagai “meminta persetujuan”.}

Contoh kalimat dalam novel "Sabiru kokoro"

5. 今日は風が強いわね。（hal. 22）

'Hari ini angin bertiup kencang sekali ya.'

(Situasi: Didalam kafe Morizaki berkata kepada Mizue sambil memandang ke luar melalui jendela)

Analisis penggunaan $\mathfrak{\mho}_{2}$ : Ketika Morizaki mengatakan hal ini karena ia melihat angin bertiup kencang dan Mizue juga melihat hal yang sama tetapi kesimpulan mereka berdua belum tentu sama sehingga Morizaki meminta persetujuan kepada Mizue.

6. 羊歯が生えてるんだね。（hal. 60 )

'Tumbuh pohon pakis ya.'

(Situasi: Jumpei seorang pengusaha toko buku yang sudah berkeluarga mengatakan kepada Akiko \{wanita simpanannya\} sambil menarik nafas bahwa dibelakang rumah yang akan mereka beli ternyata tumbuh pohon pakis)

Analisis penggunaan $\mathfrak{l}_{2}$ : Jumpei dan Akiko pergi ke rumah yang akan mereka beli. Disana mereka melihat adanya pohon pakis. Jumpe suka sekali melihat adanya tumbuhan pakis di rumah yang akan mereka beli. Saat itu dia ingin meminta persetujuan bahwa Akiko pun suka dengan adanya pohon pakis tersebut.

7. 立派なお庭でしょうね。(hal.120)

'Taman yang indah ya.'

(Situasi: Miyata pria sebatang kara berniat menyewa rumah Tuan Kanzaki yang dirawat oleh seorang kakek-kakek. Miyata berkata tentang keadaan taman dirumah itu kepada kakek tersebut dengan gerakan seperti sedang melukis)

Analisis penggunaan $\downarrow_{2}$ : Miyata sangat kagum dengan taman tersebut sementara kakek disebelahnya hanya melihat dengan perasaaan biasa saja.Melihat kejadian tersebut Miyata menjadi bertanya-tanya apakah kakek tersebut setuju bahwa taman tersebut adalah taman yang indah, sehingga Miyata mengungkapkan kalimat yang mengandung makna meminta persetujuan.

8. 今日は、ちょっと冷えますね。（hal. 130）

'Hari ini, agak dingin ya.'

(Situasi: ketika bertemu ditaman, Miyata yang mengontrak rumah Kanzaki berkata kepada sang tuan rumah dengan wajah pucat seperti merasa bersalah)

Analisis penggunaan $\downarrow$ : Miyata bertemu dengan Kanzaki didepan rumah, karena berada diluar, Miyata merasa kedinginan. Ketika melihat Kanzaki, dia mencoba memulai percakapan dengan meminta persetujuan dari Kanzaki bahwa hari ini agak dingin.

\section{Fungsi shuujoshi ne sebagai "memberi komentar tentang hal-hal yang termasuk termasuk dalam wilayah pendengar}

\section{Contoh kalimat dalam novel "Sabiru kokoro"}

9. いつも実験的なことをやってるんですね。（hal. 18）

'Kamu selalu melakukan hal yang sifatnya ujicoba ya.'

(Situasi: Mizue bercerita kepada Morizaki bahwa dia saat ini sedang menggemari sandiwara yang temanya diambil dari nama sel)

Analisis penggunaan $\downarrow_{2}$ : Setelah mendengar cerita Mizue mengenai kegiatan-kegiatannya yang selalu bersifat ujicoba, seperti penelitian mengenai sel hidup, Morizaki mencoba memberikan komentar mengenai hal itu.

10. 虂骨といってもいいくらい、愛情を告白しているのね。（hal. 28）

'kamu ini begitu polosnya untuk mengekspresikan cintamu ya.' 
(Situasi: Didalam kafe Mizue bercerita kepada Morizaki mengenai dirinya yang akan menjadi istri Ai, karena Ai sudah bercerai dengan istrinya)

Analisis penggunaan $\sqrt{2}$ : Setelah mengetahui bahwa Mizue menyatakan cintanya kepada Ai, Morizaki berkomentar. Meskipun “ね” disini sepintas terlihat seperti meminta penegasan tetapi ini adalah komentar dimana Morizaki mengomentari perjalan cinta dari Mizue.

11.まあ、そのくらいの根性がないとね。（hal. 204）

'Memang, akan sulit kalau kamu tidak punya niat sekuat itu ya.'

(Situasi: Didalam sebuah ruangan Sachiko sang tuan rumah tempat Kinoko melamar pekerjaan yang awalnya diam saja, tiba-tiba berkata kepada Kinoko sambil menatap wajah Kinoko)

Analisis penggunaan ね: Pada saat diwawancarai Kinoko menceritakan semua tentang keberadaan dirinya yang pergi meninggalkan suami dan anaknya, mendengar cerita tersebut Sachiko memberi komentar tentang diri Kinoko, bahwa tekad yang dimiliki Kinoko jarang dimiliki oleh orang biasa lainnya.

12.ああ、エビのことね。エビが好きなのね。（hal. $213 ）$

'Oh, udang ya, kamu suka udang ya.'

(Situasi: Di taman Kinoko bertemu Midori salah seorang pembantu yang lemah ingatan yang sudah dianggap keluarga oleh Umeko)

Analisis penggunaan $\downarrow$ : Kinoko memberi komentar bahwa Midori suka udang karena ternyata benda yang paling disukai yang sebelumnya dijelaskan ciri-cirinya oleh Midori adalah udang.

\section{Fungsi Shuujoshi Ne sebagai Penyempurnaan Pendapat Penutur Berdasarkan Informasi Tambahan dari Pendengar.}

\section{Contoh kalimat dalam novel "Sabiru kokoro"}

13. 大家さんの住所を教えていただけませんかね。（hal. 66）

'Anda, dapat memberitahukan alamat tuan tanah kan ?'

(Situasi: Jumpei yang ingin membeli sebuah rumah berkata kepada broker rumah dalam percakapan telepon)

Analisis penggunaan $\downarrow$ : Jumpei sebagai penutur berusaha mendapatkan informasi tambahan dari broker rumah mengenai alamat tuan tanah, untuk melengkapi informasi yang diinginkannya.

14.さあ、これでいいですかね。（hal.113）

'Nah, kalau begini sudah ok kan.'

(Situasi: Didalam rumah yang akan disewa Miyata, pegawai wanita dari perusahaan real estet menyalakan lampu agar ruangan menjadi terang)

Analisis penggunaan $\gtrless^{2}$ : Setelah lampu menyala Pegawai wanita dari perusahaan real estet merasa situasinya sudah ok, untuk melengkapi informasi bagi dirinya apakah situasinya sudah baik apa belum, ia meminta informasi tambahan dari Miyata.

15. どうしてですかね? (hal. 118 )

'kenapa ya.'

(Situasi: Didepan rumah yang disewanya Miyata berkata kepada sang kakek perawat rumah) Analisis penggunaan $\gtrless_{2}$ : Pada saat itu Miyata dan sang kakek tengah membicarakan keadaan Kanzaki sang pemilik rumah yang keadannya sangat misterius, tetapi setelah mereka bercakap-cakap Miyata merasa masih kekurangan informasi sehingga untuk menyempurnakan informasi ia bertanya kepada sang kakek sebagai informan yang mempunyai informasi lebih lengkap.

16. あの庭や屋敷のほうに手は入れないんですかね。（hal. 120）

'Saya tidak boleh masuk ke taman dan rumah utama itu ya.' 
(Situasi: Didepan rumah yang disewanya Miyata berkata kepada sang kakek perawat rumah) Analisis penggunaan $\downarrow$ : Miyata yang sangat tertarik dengan taman dan rumah utama yang terdapat didalam rumah yang disewanya, mendapatkan informasi bahwa orang lain tidak boleh masuk kedalam taman dan rumah tersebut. Karena sangat ingin masuk Miyata merasa perlu menyempurnakan informasinya apakah sebagai pengontrak ia dapat masuk atau tidak.

\section{Fungsi Shuujoshi Ne sebagai bentuk Menuntut/Memohon kepada Pendengar}

\section{Contoh kalimat dalam novel "Sabiru kokoro"}

17. 皆さんも勉強してね。（hal. 18）

'Kalian semua juga harus belajar ya.'

(Situasi: Mizue berkata kepada murid-muridnya didalam kelas pada saat mengakhiri pelajaran)

Analisis penggunaan $\downarrow$ : Ketertarikan murid-muridnya akan sel hidup membuat Mizue bersemangat dan pada saat mengakhiri pelajaran Mizue mengharapkan agar murid-muridnya tidak melupakan pelajaran yang baru saja mereka selesaikan. Agar murid-muridnya tidak sampai lupa Mizue menggunakan kalimat permohonan agar mereka juga belajar.

18.じや、お互いに準備しましょう。あなたもちゃんとしてね。（hal. 56 ）

'Kalau begitu kita harus bersiap-siap. Kamu juga harus benar-benar mempersiapkannya ya.'

(Situasi: Didalam rumahnya Akiko berkata kepada Jumpe dengan suara penuh rasa riang dan antusias)

Analisis penggunaan $\downarrow$ : Setelah berhubungan selama empat tahun, Jumpei dan Akiko akhirnya sepakat untuk tinggal satu rumah. Agar mereka dapat segera bersatu Akiko memohon kepada Jumpei agar dia pun serius untuk segera mempersiapkannya.

19.これからはあなたが計算して、買い物に行ってくださいね。（hal. 209）

'Mulai saat ini kamu yang mengatur dan yang pergi berbelanja ya.'

(Situasi: Pada saat berada di dapur Umeko berkata kepada Kinoko seperti orang yang sedang memohon)

Analisis penggunaan $\downarrow_{2}$ : Pada hari pertama kerja Kinoko, Umeko meminta agar dia memasak untuk makan siang, tetapi Kinoko bingung harus memasak apa dengan biaya 500 yen per orang per hari. Melihat Kinoko bingung Umeko memohon agar Kinoko yang mengatur dan yang pergi berbelanja

\section{Fungsi Shuujoshi Yo}

Berdasarkan analisis yang telah penulis lakukan dalam korpus data yaitu novel "sabiru kokoro", fungsi-fungsi shuujoshi yo dapat dengan jelas mengapresiasikan situasi dan perasaan si pemakainya. Fungsi-fungsi yang penulis temukan adalah sebagai berikut:

\section{Fungsi Shuujoshi Yo sebagai “Menyangkal/Membantah Penilaian dan Pertimbangan Pendengar yang Dianggap Berbeda Dengannya”.}

\section{Contoh kalimat dalam novel "Sabiru kokoro"}

20. ええ。でも、芝居自体は愉快だし、面白いんですよ。(hal.18)

'Iya, tetapi sandiwara itu sendiri sangat menarik dan menyenangkan loh.'

(Situasi: Mizue bercerita kepada Morizaki mengenai tema sandiwara yang diambil dari proses terjadinya sel. Mendengar hal tersebut Morizaki berkomentar bahwa untuk memahami hal itu merupakan sesuatu yang sulit.)

Analisis penggunaan $よ$ : Setelah Morizaki berkomentar bahwa drama tersebut adalah sesuatu yang sulit, Mizue memberikan bantahan mengenai penilaian Morizaki tersebut, dengan mengatakan bahwa drama itu sendiri sebetulnya merupakan sesuatu yang menarik. 
21. いや、違いますよ。(hal. 37)

'bukan, bukan begitu kok.'

(Situasi: Didalam teater milik Ai, Morizaki bertanya kepada Ai apakah dia bercerai dengan istirinya dikarenakan keberadaan Mizue yang mencintai dirinya)

Analisis penggunaan $\mathfrak{L}:$ Ai sangat terkejut dengan pertanyaan Morizaki, karena dia merasa tidak bercerai dengan istrinya. Meskipun sedang bingung Ai langsung membantah pertanyaan dari Morizaki tersebut.

22. いいえ、買う気はないわよ。(hal. 70)

'Tidak, saya tidak berniat untuk membelinya kok.

(Situasi: Setelah tiba dihotel Akiko dan Jumpei bercakap-cakap. Jumpei berkomentar bahwa rumah yang akan mereka beli itu angker, karena pernah terjadi peristiwa bunuh diri)

Analisis penggunaan $\mathfrak{L}$ : Sebenarnya Akiko mengetahui bahwa rumah tersebut angker dari pegawai perusahaan real estet. Dia kemudian mengatakan hal itu pada Jumpei. Menanggapinya, Jumpei berkata, kenapa kalau sudah tahu masih akan membelinya juga. Akiko langsung membantah sebenarnya ia tidak ada niat untuk membelinya. Tapi karena uang yang digunakan untuk membeli rumah tersebut adalah uang pribadi Akiko, dia merasa tidak perlu berunding dengan Jumpei.

23.でも、今のストーブはそういうこはありませんよ。(hal.131)

'Tapi, alat pemanas saya yang sekarang ini tidak seperti itu kok.'

(Situasi: Miyata berbasa-basi kepada Ny. Kanzaki dengan mengatakan bahwa cuaca dingin sekali. Tiba-tiba tanpa alasan yang jelas Ny.Kanzaki melarang Miyata memakai alat pemanas yang mengunakan bahan bakar/ minyak tanah)

Analisis penggunaan $\mathfrak{L}$ : Miyata merasa heran kenapa ia tidak boleh menggunakan pemanas yang berbahan bakar. Karena itu Miyata mencoba membantah pernyataan Ny.Kanzaki, bahwa pemanas jaman sekarang tidak menggunakan minyak tanah.

\section{Fungsi Shuujoshi Yo sebagai “Mengingatkan Hal yang Kiranya Terlupakan oleh Pendengar dan Mengutarakan Hal yang Diingat oleh Penutur"}

\section{Contoh kalimat dalam novel "Sabiru kokoro"}

24.相手はあなたと同じ教師よ。(hal. 11 )

'Pacarku juga sama dengan kamu, seorang guru loh.'

(Situasi: Morizaki dan Mizue bercerita tentang pacar mereka masing-masing. Pada saat itu Morizaki menceritakan profesi dari pasangannya)

Analisis penggunaan $よ$ : Pada saat bercerita mengenai keberadaan pacar masing-masing, topik yang mereka bicarakan berganti mengenai pekerjaan. Tiba-tiba Morizaki ingat akan profesi pacarnya sebagai seorang guru. Sehingga ia mengutarakan hal yang diingatnya tersebut.

25. 一番に入れてますよ。(hal. 148 )

'Sudah saya masukkan dinomor satu loh.'

(Situasi: Sakurai ketua geng yakuza bersama salah seorang anggotanya yang bernama Kitamura, berkeliling mengontrol wilayah kekuasaan mereka dan berhenti disebuah toko)

Analisis penggunaan $\mathfrak{L}$ : Tiba didepan toko, Kitamura menyuruh pegawai toko tersebut untuk menyimpan nomor teleponnya. Hal ini dilakukan supaya jika terjadi sesuatu, Kitamura mudah dihubungi. Setelah memasukkan nomor telepon milik Kitamura, pegawai toko tersebut mencoba mengingatkan Kitamura bahwa nomor teleponnya sudah dimasukkan.

26.ささきご主人から電話があったわよ。(hal. 184)

'Tadi ada telepon dari suami anda loh.'

(Situasi: Kinoko pergi meninggalkan rumahnya, karena malu rahasia selingkuhnya terbongkar. Dia menginap dirumah sahabatnya yang bernama Chikako) 
Analisis penggunaan よ: Sebelum Kinoko tiba dirumah Chikako, suami Kinoko menelepon kerumah Chikako. Ketika Kinoko tiba dirumahnya, Chikako heran melihat penampilan Kinoko, dan bertanya apa yang terjadi. Setelah mendapat penjelasan dari Kinoko, dia mencoba mengutarakan hal yang diingatnya kepada Kinoko, bahwa tadi suami Kinoko menelepon kerumahnya.

27. おにいちゃーん。お昼御飯ですよ。(hal. 214)

'Kak... waktunya makan siang loh.'

(Situasi: Yasuo yang sakit-sakitan lebih sering tinggal dilantai dua. Midori yang kesehariannya merawat Yasuo tiba-tiba memanggil Yasuo sambil menengadah keatas dan melambaikan tangannya)

Analisis penggunaan $よ$ : Kinoko memberitahu midori bahwa sudah waktunya untuk makan siang. Setelah mendapatkan informasi tersebut, Dia mengingat bahwa Yasuo juga belum makan. Sehingga dia mencoba mengutarakan hal yang diingatnya dengan memanggil Yasuo agar segera makan siang.

\section{Fungsi Shuujoshi Yo sebagai “Menyampaikan Hal yang tidak Disadari dan tidak Diketahui oleh Pendengar”.}

\section{Contoh kalimat dalam novel "Sabiru kokoro"}

28. そうよ。だから、ここはあなたのお庭よ。(hal. 60 )

'Iya. karena itu, taman ini milik kamu loh.'

(Situasi: Jumpei dan Akiko \{wanita simpanannya\} melihat-lihat rumah yang akan mereka beli yang ternyata tumbuh pohon pakis dihalaman belakang rumah)

Analisis penggunaan $よ$ : Jumpei yang sangat menyukai pohon pakis, sangat senang dengan adanya taman yang penuh dengan pohon pakis tersebut. Jumpei tidak sadar bahwa Akiko sengaja memilih rumah tersebut demi Jumpei. Sehingga Akiko berusaha menyampaikan hal yang tidak disadari oleh Jumpei bahwa taman tersebut memang ditujukan untuk Jumpei.

29. せんせ、でも、そのくらいの酔っ払いたくさんいますよ。(hal. 88 )

'Pak, kalau mabuk seperti itu, orang lain juga banyak kok.'

(Situasi: Pada saat bertemu didalam ruang loker, Sawanobori salah seorang murid Iwasa, bercerita kepada Iwasa mengenai perangai gurunya kalau sedang mabuk)

Analisis penggunaan よ: Iwasa mendapat informasi dari Sawanobori bahwa ia sering membuat keonaran kalau sedang mabuk. Hal ini membuat Iwasa merasa risih dengan sikapnya tersebut. Melihat hal ini Sawanobori mencoba menghibur Iwasa dengan mengatakan hal yang yang tidak disadari oleh Iwasa bahwa orang lain pun akan berbuat hal yang sama jika sedang mabuk.

30.あなた、お化けを見たような顔してるわよ。(hal. 183 )

'Kinoko, wajahmu seperti orang habis melihat hantu saja loh.'

(Situasi: Kinoko tiba dirumah Chikako dengan wajah pucat, Chikako berkata kepada Kinoko sambil menatap wajah Kinoko dengan rasa iba)

Analisis penggunaan $よ$ : Kinoko pergi meninggalkan rumahnya, menghindari kejaran istri dari pria selingkuhannya. Dia pergi menuju rumah sahabatnya yang bernama Chikako dengan tergesa-gesa. Chikako terkejut melihat kedatangan Kinoko yang serba mendadak dan berpenampilan berantakan. Melihat hal itu Chikako mencoba memberi tahu hal yang tidak disadari Kinoko, bahwa wajahnya pucat seperti baru melihat hantu.

31. 前より若くなったよ。(hal. 217)

'Dibandingkan dulu, sekarang ibu lebih muda loh.'

(Situasi: Sambil duduk berhadapan didalam sebuah kafe, Kinoko bertemu dengan putrinya yang bernama Aoi dan mereka saling bertukar cerita mengenai kehidupan mereka masingmasing)

Analisis penggunaan よ: Setelah setengah tahun meninggalkan rumahnya, akhirnya Kinoko 
dapat bertemu dengan putrinya. Dia bertanya bagaimana kabar putrinya tersebut. Setelah menjawab dengan baik-baik saja, Ai melihat bahwa Ibunya telihat lebih muda dari sebelumnya, dan hal ini tidak disadari oleh Kinoko. Sehingga Ai mencoba menyampaikan hal yang tidak disadari oleh Kinoko tersebut.

\section{Fungsi Shuujoshi Yo sebagai "Menyampaikan Permohonan kepada Pendengar dimana didalamnya terdapat Kalimat Perintah, Larangan dan Bujukan”.}

Contoh kalimat dalam novel "Sabiru kokoro"

32. わかったら、仕事しろよ。(hal. 151)

'Kalau sudah mengerti, kerjakan dong.'

(Situasi: Sakurai mendapati seorang pemuda yang bernama Shimajiri sedang makan didepan toko yang menjadi wilayah kekuasaannya)

Analisis penggunaan よ: Ketika berkeliling diwilayah kekuasaannya, Sakurai bertemu dengan Shimajiri. Kemudian Sakurai menegur pemuda tersebut, menyuruh makan dulu baru berjaga didepan. Shimajiri mengangguk tanda mengerti.. Sehingga Sakurai memerintahkan agar Shimajiri mengerjakan hal yang dikatakannya, kalau memang sudah mengerti.

33. 早く出て来てくださいよ。(hal. 180)

'Kamu, cepat keluar dong.'

(Situasi: Sambil mengetuk pintu keras-keras Ny.Aoshima istri dari pria selingkuhan Kinoko datang melabrak kerumah Kinoko)

Analisis penggunaan $よ$ : Kisah selingkuh Kinoko dengan Aoshima, akhirnya sampai ke telinga Ny.Aoshima. Untuk membuktikannya Ny.Aoshima datang kerumah Kinoko. Karena Kinoko tidak mau keluar, Ny.Aoshima memerintahkan wanita itu agar segera keluar.

34. ミドリちゃん。降りてきてよ。(hal. 207)

'Midori... turun dong.'

(Situasi: Ketika Kinoko tiba dirumah Shigeko, Shigeko berteriak kearah loteng memanggil Midori untuk diperkenalkan dengan Kinoko)

Analisis penggunaan $\mathfrak{L}$ : Akhirnya Kinoko memilih bekerja dirumah Shigeko. Pada hari pertama Shigeko memperkenalkannya kepada seluruh penghuni rumah. Karena Midori sedang berada diatas, Shigeko memerintahkan Midori turun agar berkenalan dengan Kinoko.

35. 懐かしいこと言うなよ。(hal. 173 )

'Jangan bicara masa lalu dong.'

(Situasi: Sakurai dan Kitamura berjalan bersama ditrotoar setelah mereka pulang dari pesta minum-minum )

Analisis penggunaan よ: Dalam perjalanan pulang Kitamura bertanya kepada Sakurai mengenai tugas yang akan diberikan kepada Shimajiri. Karena Kitamura dan Sakurai adalah sahabat lama, Kitamura memanggil Sakurai dengan julukan lama, pada saat mereka masih remaja. Sehingga Sakurai marah dan melarang Kitamura memanggilnya dengan julukan yang tersebut.

Tabel 1 berikut adalah analisis fungsi ne dan yo berdasarkan maknanya dalam bahasa Indonesia berdasarkan persepsi penulis. 
Tabel 1 Fungsi Ne dan Yo

\begin{tabular}{|c|c|c|c|}
\hline No & Jenis Shuujoshi & Terjemahan & Fungsi \\
\hline \multirow[t]{5}{*}{1} & 小 & Ya, Kan & $\begin{array}{l}\text { 1. Digunakan ketika penutur meminta kepastian/ } \\
\text { penegasan }\end{array}$ \\
\hline & 永 & Ya, Loh & 2. Digunakan ketika penutur meminta persetujuan \\
\hline & 放 & Ya, Nih & $\begin{array}{l}\text { 3. Digunakan ketika penutur memberi komentar hal-hal } \\
\text { yang termasuk dalam wilayah pendengar }\end{array}$ \\
\hline & ね & Ya, Kan & $\begin{array}{l}\text { 4. Digunakan ketika penyempurnaan pendapat penutur } \\
\text { berdasarkan informasi tambahan dari pendengar }\end{array}$ \\
\hline & ね & Ya & $\begin{array}{l}\text { 5. Digunakan ketika penutur menuntut atau memohon } \\
\text { kepada pendengar }\end{array}$ \\
\hline \multirow[t]{4}{*}{2} & よ & Loh, Kok, & $\begin{array}{l}\text { 1. Digunakan ketika penutur membantah penilaian dan } \\
\text { pertimbamngan pendengar yang dianggap berbeda } \\
\text { dengannya }\end{array}$ \\
\hline & よ & Loh, & $\begin{array}{l}\text { 2. Digunakan ketika penutur mengingatkan hal yang } \\
\text { kiranya terlupakan oleh pendengar dan mengutarakan } \\
\text { hal yang diingat oleh penutur }\end{array}$ \\
\hline & $よ$ & Kok, Loh, & $\begin{array}{l}\text { 3. Digunakan ketika penutur menyampaikan hal yang } \\
\text { tidak disadari dan tidak diketahui oleh pendengar }\end{array}$ \\
\hline & よ & Dong, Lah, & $\begin{array}{l}\text { 4. Digunakan ketika penutur menyampaikan } \\
\text { permohonan kepada pendengar dimana di dalamnya } \\
\text { terdapat kalimat perintah, larangan, dan bujukan }\end{array}$ \\
\hline
\end{tabular}

\section{SIMPULAN}

Dengan melihat hasil analisa data, maka penulis mengambil kesimpulan bahwa shuujoshi ne, digunakan oleh penutur saat dia mempunyai kesamaan persepsi dengan pendengarnya. Dalam pemaknaannya shuujoshi ne mempunyai beberapa fungsi yaitu :

- Shuujoshi ne sebagai "meminta kepastian/penegasan" dimana ne diterjemahkan sebagai ya, kan.

- Shuujoshi ne sebagai "meminta persetujuan" dimana ne diterjamahkan sebagai ya, $\underline{\text { loh. }}$

- Shuujoshi ne sebagai "memberi komentar tentang hal-hal yang termasuk dalam wilayah pendengar" dimana ne diterjemahkan sebagai ya, nih.

- Shuujoshi ne sebagai "penyempurnaan pendapat penutur berdasarkan informasi tambahan dari pendengar" dimana ne diterjemahkan sebagai ya, kan.

- Shuujoshi ne sebagai "bentuk menuntut/memohon kepada pendengar" dimana ne diterjemahkan sebagai ya. Dengan melihat hasil analisa data, maka penulis mengambil kesimpulan bahwa Shuujoshi ne, digunakan oleh penutur saat dia mempunyai kesamaan persepsi dengan pendengarnya. Penggunaan shuujoshi yo, terjadi apabila pernyataan penutur berbeda dengan persepsi si pendengarnya.Dalam pemaknaannya shuujoshi yo mempunyai beberapa fungsi yaitu :

- Shuujoshi yo sebagai "menyangkal/membantah penilaian dan pertimbangan pendengar yang dianggap berbeda dengannya" dimana yo diterjemahkan sebagai loh, $\underline{\mathrm{kok}}$,

- Shuujoshi yo sebagai "mengingatkan hal yang kiranya terlupakan oleh pendengar dan mengutarakan hal yang diingat oleh penutur" dimana yo diterjemahkan sebagai loh,

- Shuujoshi yo sebagai "menyampaikan hal yang tidak disadari dan tidak diketahui oleh pendengar" dimana yo diterjemahkan sebagai kok, loh.

- Shuujoshi yo sebagai "menyampaikan permohonan kepada pendengar dimana didalamnya terdapat kalimat perintah, larangan, dan bujukan" dimana yo diterjemahkan sebagai dong, lah, ya,

Demikianlah analisis mengenai fungsi ne dan yo berdasarkan maknanya yang contoh-contoh kalimatnya diambil dari novel "Sabiru kokoro" karya Kirino Natsuo. 


\section{DAFTAR PUSTAKA}

桐野夏雄. (1997).「錆びる心」.東京: 分書春秋.

益岡隆志 (1991) 「モダリティの文法」東京: くろしお出版

庭 三郎 (2004) 「現代日本語文法概説」 Diunduh dari http://www.geocities.jp/ niwasaburoo/index.html

Sudjanto \& Dahidi, A. (2004). Pengantar Linguistik Bahasa Jepang. Jakarta: Kesaint Blanc

Sudrajat, A. (2001). Tata Bahasa Jepang Lengkap. Bandung: Pionir Jaya.

\section{RIWAYAT PENULIS}

Rudi Hartono Manurung lahir di kota Jakarta pada 16 Nopember 1974. Penulis menamatkan pendidikan S1 di Binus University dalam bidang Sastra Jepang pada 2005. Saat ini bekerja sebagai dosen/Sekjur di Binus University. 